\title{
Potential impact of invasive surgical procedures on primary tumor growth and metastasis
}

\author{
Maria Alieva ${ }^{1} \cdot$ Jacco van Rheenen ${ }^{2} \cdot$ Marike L. D. Broekman ${ }^{3}$
}

Received: 15 February 2018 / Accepted: 30 April 2018 / Published online: 4 May 2018

(c) The Author(s) 2018

\begin{abstract}
Surgical procedures such as tumor resection and biopsy are still the gold standard for diagnosis and (determination of) treatment of solid tumors, and are prognostically beneficial for patients. However, growing evidence suggests that even a minor surgical trauma can influence several (patho) physiological processes that might promote postoperative metastatic spread and tumor recurrence. Local effects include tumor seeding and a wound healing response that can promote tumor cell migration, proliferation, differentiation, extracellular matrix remodeling, angiogenesis and extravasation. In addition, local and systemic immunosuppression impairs antitumor immunity and contributes to tumor cell survival. Surgical manipulation of the tumor can result in cancer cell release into the circulation, thus increasing the chance of tumor cell dissemination. To prevent these undesired effects of surgical interventions, therapeutic strategies targeting immune response exacerbation or alteration have been proposed. This review summarizes the current literature regarding these local, systemic and secondary site effects of surgical interventions on tumor progression and dissemination, and discusses studies that aimed to identify potential therapeutic approaches to prevent these effects in order to further increase the clinical benefit from surgical procedures.
\end{abstract}

Keywords Tumor resection $\cdot$ Biopsy $\cdot$ Metastasis $\cdot$ Tumor cell behavior $\cdot$ Immune suppression $\cdot$ Wound healing

\begin{tabular}{ll}
\multicolumn{2}{l}{ Abbreviations } \\
FNAs & Fine needle aspirations \\
LMS & Leptomeningeal spread \\
SRS & Stereotactic radiosurgery \\
Tregs & Regulatory T cells \\
EMT & Epithelial to mesenchymal transition \\
CTCs & Circulatory tumor cells \\
NK & Natural killers \\
NETs & Neutrophil extracellular traps \\
HIF & Hypoxia inducible factors \\
RBCs & Red blood cells
\end{tabular}

Maria Alieva

m.alieva@prinsesmaximacentrum.nl

1 Princess Máxima Center for Pediatric Oncology, Uppsalalaan 8, 3584 CT Utrecht, The Netherlands

2 Department of Molecular Pathology, Oncode Institute, Netherlands Cancer Institute, Plesmanlaan 121, 1066 CX Amsterdam, The Netherlands

3 Department of Neurology \& Neurosurgery, Brain Center Rudolf Magnus, University Medical Center Utrecht, Heidelberglaan 100, 3584 CX Utrecht, The Netherlands

\section{Introduction}

Tumor tissue resection and biopsy are still indispensable for diagnosis, cytoreduction and determination of subsequent treatment strategies of solid tumors and, importantly, to extend the patients' lifespan or contribute to their cure. However, also a wide range of potential undesired effects have been associated with these procedures. Negative consequences of tumor invasive procedures not only include postoperative complications, such as hemorrhage, surgical site infections and venous-thromboembolic complications [1-3], but also changes affecting the remaining tumor cells, such as increased survival, proliferation and migration $[4,5]$. An increasing body of evidence from clinical and experimental studies suggests that surgical trauma caused by biopsies or resections gives rise to a series of local and systemic events that can potentially promote tumor progression and metastatic disease [4, 6-12]. Surgical interventions disrupt the tumor and the surrounding tissue and result in tumor cell displacement to healthy tissue and release into the circulation. Moreover the inflicted surgical trauma initiates a wound healing response that activates a series of humoral and cellular cascades aimed at closing the wound [13]. While necessary for normal tissue repair, the local and systemic 
alteration of the innate and adaptive immune responses can stimulate tumor cell malignant behavior, survival, angiogenesis and extravasation of circulating tumor cells.

These undesired effects have the potential to affect tumor progression and spread. However, this does not imply that surgical resection or biopsy should be abandoned since these effects may only hold true for a subset of patients and the prognostic benefit of these procedures still strongly outweigh their negative effects. Nevertheless, it will be important to fully understand their impact on tumor pathology in order to prevent these effects and develop adjuvant treatments that would make these procedures even safer and more beneficial for the patients.

In this review, we summarize existing data that illustrates the effects of surgery on tumor progression and discuss potential strategies to circumvent these undesired effects of surgical procedures.

\section{Local effects of surgery}

\section{Biopsies and tumor cell seeding}

Fine needle aspirations (FNAs), in which a thin fine-gauge needle is inserted into the core of the tumor to aspirate tumor cells, are commonly performed to obtain tissue for diagnosis. This procedure has been associated not only with standard surgical complications as surgical site infections and hemorrhage, but also with a risk of tumor cell seeding along the needle track into the adjacent tissues. This risk is inherent to the procedure in which a needle transgresses and disrupts the tumor and is withdrawn. Histological evidence suggests that upon FNA tumor cells can be found in adjacent tissues [14-16]. However, some studies question the viability of the remaining tumor cells. For example, in breast tumors undergoing biopsy the incidence of tumor cell seeding in the needle track seemed to decline as the time between the biopsy and the subsequent resection increased, suggesting that the displaced cells rarely survive [17].

The use of larger needles has also been associated with tumor seeding into the adjacent tissues. For example in brain malignancies, tumor cells could be found in the needle track after biopsy of gliomas [18, 19] (Fig. 1) or of brain metastases [20,21]. However, the incidence of viable tumors and tumor recurrences along the track is low and hard to quantify. For hepatocellular carcinoma, a recent meta-analysis of the available literature showed that, overall the pooled estimate of a patient with seeding per 100 patients is 0.027 and that, per year the pooled estimate of a patient with seeding per 100 patients is 0.009 [22]. For other cancers, where FNA is a common practice, such as thyroid cancer, needle track seeding is extremely rare and only a few cases have been reported [23]. Percutaneous FNA, performed on pancreatic tissue has also been associated with coelomic seeding [24]. However distinct studies present conflicting results on the incidence of seeding and its risk for tumor progression [25]. The use of endoscopic ultrasound-FNA allows a more accurate lesion sampling and thus may eliminate the risk of coelomic seeding [26]. The risk of tumor seeding after needle biopsy in retroperitoneal sarcoma is estimated to be $0.37 \%$, based on pooled data from four tertiary care centers [27-29]. Even though the data is limited, few studies indicate that the use of vacuum assisted biopsy devices might reduce the risk of tumor seeding compared to the use of traditional devices $[17,30]$.

\section{Effect of tumor resections on tumor cell seeding}

For many solid tumor types, resection is part of the treatment plan. Often, the aim of surgery is to completely resect a tumor (gross total resection), but partial resections are sometimes the only clinical option. Various tumors including chordoma [31] and mixed epithelial stromal tumor of the kidney [32] have also shown evidence of tumor seeding as a result of partial resections. Unfortunately, even gross total resection of tumors can result in local dissemination of cells. For example, it has been shown that piece meal resection of brain metastases increases the risk of leptomeningeal spread (LMS) resulting in worse outcomes for patients [33]. In addition, recent evidence suggests that the risk of LMS is higher after surgery followed by stereotactic radiosurgery (SRS) than after SRS alone [34].

Other examples of tumor cell dissemination after resection include port-site recurrences after laparoscopic abdominal oncological surgeries, procedures with clear advantages associated with their minimally invasive character [35]. Various factors seem to contribute to tumor seeding in this context. First, some factors might be tumor related. High-grade or high-stage tumors have been associated with a greater risk of seeding $[36,37]$. Second, there might be wound related aspects that offer a tumor supportive environment. This process can contribute to tumor metastasis and will be discussed below. Third, there might be surgery-associated factors. For example, it has been suggested that the $\mathrm{CO}_{2}$ pneumoperitoneum plays a role in the development of these metastases as well as in the development of peritoneal carcinomatosis after laparoscopic surgery [38, 39]. Dry cold $\mathrm{CO}_{2}$ might induce peritoneal damage facilitating metastases [40, 41], for example by creating a local immune suppressive micro-environment. Additionally, extensive manipulation of the tumor, has been associated with a higher risk of port site metastasis [42, 43]. Finally, not using a retrieval bag might facilitate port site metastasis [44]. To prevent these metastases, studies that aim to improve safety of surgery, for instance by identifying alternatives for the cold $\mathrm{CO}_{2}$ insufflation, like those performed in mice by Carpentiri et al., are 


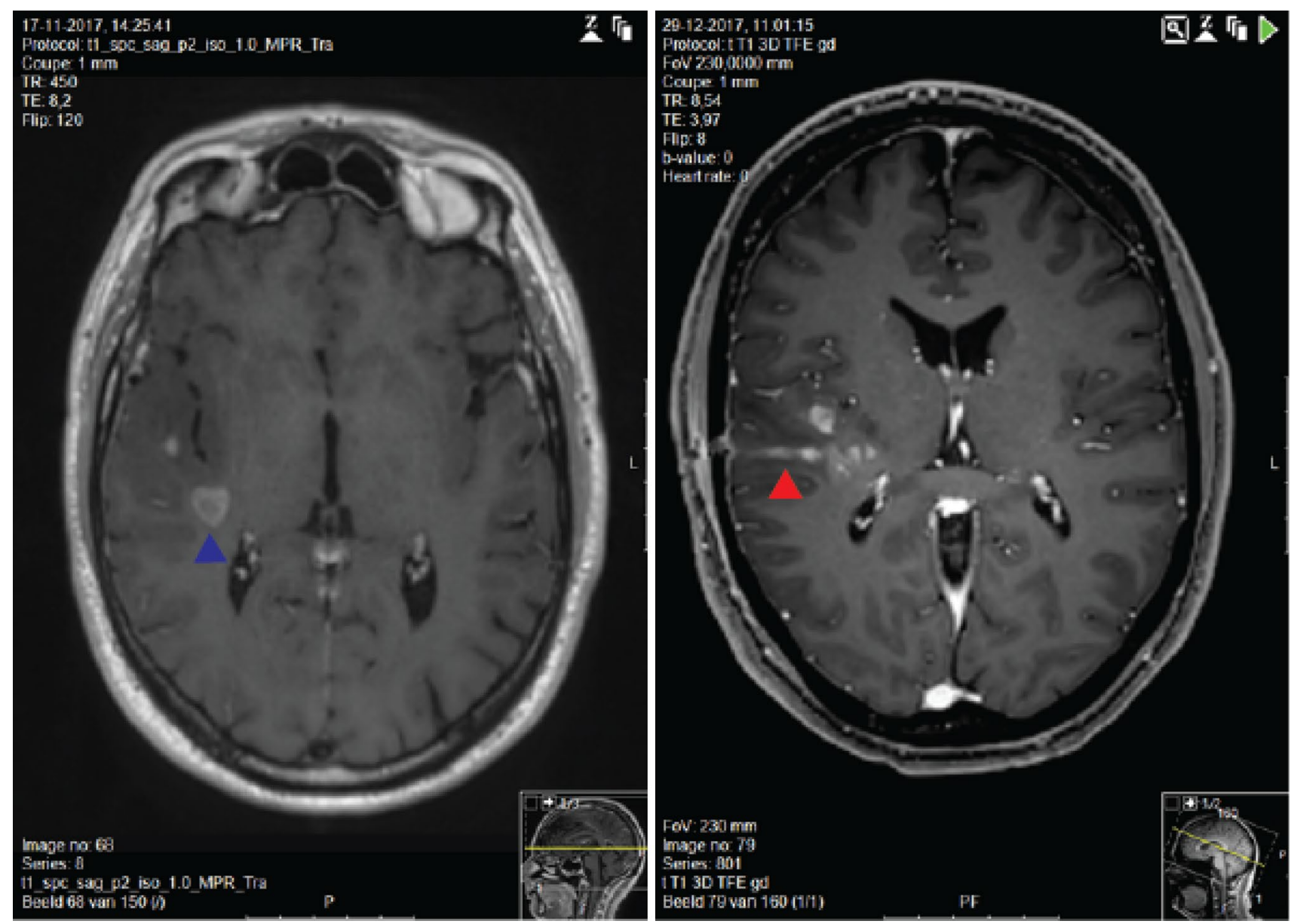

Fig. 1 Evidence of tumor seeding after needle biopsy of a glioblastoma. Six weeks after a needle biopsy of a glioblastoma (blue arrow), MRimaging shows evidence of tumor seeding along the needle track (red arrow). (Color figure online)

essential [45]. In addition, it is important that surgeons are aware of the impact of the techniques they use and that they are properly trained to minimize the risk of tumor seeding, especially since training seems to decrease the risk of these unwanted negative effects of surgery [46].

\section{Immune suppressive micro-environment}

Next to effects on tumor cell seeding, surgical procedures induce changes in the local tumor microenvironment that can impact tumor cell gene expression and behavior. Tumors are largely infiltrated by immune cells that can exert both pro-tumoral and anti-tumoral effects. To escape immune surveillance exerted by anti-tumoral effectors, tumor cells often create an immunosuppressive microenvironment that favors tumor progression and metastatic spreading [47, 48]. Surgical procedures, as tumor resection and biopsy, can even further promote immunosuppressive infiltrates in the remaining tumor mass $[49,50]$.
Both the innate and the adaptive immune systems contribute to this immune suppressive environment. In an experimental model of lung carcinoma, tumors that had undergone partial tumor resection were found infiltrated with immunosuppressive alternatively-activated macrophages and regulatory $\mathrm{T}$ cells (Tregs), which prevented CD8 T lymphocytes recruitment to the tumor and contributed to faster tumor recurrence [50]. Infiltration of these immunosuppressive cells was stimulated by high levels of TGF- $\beta$ and COX-2 found in the resection area [50]. A study of oral squamous cell carcinomas showed that the number of alternatively activated macrophages in the tumor correlates with the size of the surgical trauma, with animals undergoing tumor resection having higher numbers of alternatively activated macrophages than animals that underwent a biopsy [51]. Still, even small wounds to the tumor created by needle biopsy can rapidly promote pro-inflammatory factors such as S100A8, CXCL2, CCL3, and COX2 followed by a significant increase in the number of myeloid derived suppressor cells in the tumor [49]. Eosinophils that controversially have 
been reported as indicators of both favorable [52, 53] and poor prognosis $[54,55]$ have also been found to infiltrate the tumor after biopsy in breast cancer patients [56].

\section{Tumor cell transformation and changes in tumor cell behavior}

In addition to creating an immunosuppressive environment, infiltrating immune cells in response to surgical trauma are a source of inflammatory cytokines, chemokines and growth factors. These factors are known for their ability to promote tumor cell proliferation, differentiation and migration [57]. Numerous studies have found that tumor wounding by either resection or by biopsies stimulates tumor growth $[4,5,56$, 58-61]. Interestingly, the impact of wounding on tumor growth is distinct between tumor subtypes. For instance, luminal A breast tumor showed more Ki67 upon core needle biopsy compared to luminal B-HER2-tumors [61].

Different mechanisms explaining the local recurrence of the tumor have been proposed. Increase in levels of VEGF and endostatin in the wounded tissue potentiate neoangiogenesis, required for tumor growth [62, 63]. Mitogens, such as heparin-binding epidermal growth factor, platelet-derived growth factor, TGF- $\beta$, basic fibroblast growth factor present in the wound fluid support tumor growth rate [58, 59]. These growth factors can be secreted directly by the tumor cells, due to changes in their transcriptome [49]; or by recruited [4] and resident cells present in the wounded microenvironment [60]. Surgical trauma caused by tumor resection of brain tumors promotes reactive astrogliosis, that can either directly induce tumor proliferation thought secretion of mitogens (e.g. SDF-1) [64] or either through the recruitment of inflammatory cells such as macrophages [65].

Mathenge et al. reported that tumor biopsy promotes epithelial to mesenchymal transition (EMT) related changes in gene expression in the remaining tumor cells via an increase in TGF- $\beta$ and SOX-4 production [49]. This fundamental process in embryonic development plays a crucial role in tumor cell invasion. In glioma, surgical resection and biopsy have shown to promote tumor cell proliferation through transcriptome and secretome alterations of reactive astrocytes [60] and recruitment of pro-inflammatory monocytes to the operative site [4].

Besides increased growth rate, surgical trauma can also enhance tumor cells' migratory capacity $[4,60,66]$, a key process in tumor cell local and systemic dissemination [67, 68]. The transition from epithelial to mesenchymal state that tumor cells can undergo upon biopsy [49], is reported to be necessary for tumor cells migratory behavior $[4,69]$. Tumor cell migration and invasion in the surrounding tissue can be promoted by soluble factors as a consequence of changes in local tumor microenvironment [60] and the inflammatory cell influx [4] to the wounded site. The effects on local tumor cell invasive capacity are of particular importance for highly aggressive tumors such as high grade gliomas, in which local invasion prevents complete tumor resection and has a direct impact on patient's outcome [70, 71]. For instance, reactive astrocytosis [60] as a result of surgical resection can promote tumor cell invasion via the secretion of distinct paracrine factors (e.g. TGF- $\alpha$, CXCL12, S1P, GDNF, MMP-2, MMP9) [72-74].

The development of intravital microscopy (IVM) [75], a novel imaging technique that allows to visualize tumor cell behavior at single cell level in a living animal, has granted a deeper insight into the impact of small surgical interventions, such as biopsy, on tumor progression and determine the cellular mechanisms behind this process $[4,66]$. Using IVM, we have previously shown that biopsy-like injury induces migration and proliferation of tumor cells via recruitment of monocytes and their differentiation to macrophages [4]. Over the last decades it has been extensively reported that tumor associated macrophages are able to promote tumor cell migration thought secretion of matrix-remodeling proteins, cytokines and chemokines (e.g. MMP-2, MMP-9, TNF- $\alpha$, VEGF, TGF- $\beta$, EGF) [76-80]. Some of these factors and others can also stimulate tumor proliferation and survival (e.g. EGF, PDGF, TGF- $\beta 1$, HGF and FGF-2) [79, $81,82]$. Another study using IVM has shown that next to their ability to invade the surrounding tissue, human glioma cells have been shown to repopulate the surgical lesion area through directed migration to the wounded site [66]. In some models, it has been shown that this recolonization is at least in part mediated by tumor microtubes that form a tumor cell network and contribute to tumor cell invasion, proliferation in unlesioned tumor and to radiotherapy resistance [83]. Upon surgery, the neighboring tumor cells are able to extend new tumor microtubes and direct newly formed tumor cell nuclei towards the lesioned area to repopulate it [66].

\section{Systemic effects of surgery}

\section{Tumor cell release}

With the advance of successful treatments that target primary tumor sites, metastatic disease management and prevention has become the main challenge for most solid tumor treatment strategies [84]. However, surgical trauma results in systemic and secondary site changes that might favor the formation of new metastases and potentiate the growth of pre-existent micrometastases.

Because tumor cell dissemination to distant organs occurs via shedding of circulatory tumor cells (CTCs) into the lymphatic and blood vasculature, high CTC numbers are closely associated with metastatic disease progression and survival $[85,86]$. Numerous studies from different types of cancer 
have reported cancer cell release into the circulation as a result of biopsy and surgical resection [49, 87-94].

Even non-invasive medical interventions such as external tumor palpation have been shown to lead to increased numbers of CTCs during and immediately after the procedure in subcutaneous models of melanoma and breast cancer [94], suggesting that tumor cells release into the circulation is susceptible to external manipulation. However, CTCs release upon surgery and its impact on patients' prognosis is still controversial, since some studies show no increase in CTC counts before and after surgery [95], while others find that CTC counts after surgery are not associated with recurrence free survival or overall survival [96].

Interestingly, a time-course experiment over several weeks performed by Juralti et al. found that CTC dynamics increased immediately after punch biopsy and stayed elevated for 6 weeks after the procedure [93], while complete tumor resection led to a decrease in CTC counts. This difference is likely to be due to the high efficiency of tumor cell resection that can be achieved in a subcutaneous pre-clinical model where the complete primary tumor can be eliminated, and thus the source of CTCs. However, in the clinic complete tumor resection can be very challenging, making partial or subtotal resections a reality [97-99]. In these cases the remaining tumor cells can be a source of CTCs. In line with this notion Juralti et al. found that incomplete tumor resection led to an increased number of CTCs [93].

The mechanisms of CTC mobilization in the blood upon surgical trauma have yet to be clarified. The immediate shedding of CTCs in the bloodstream indicates passive intravasation due to mechanical pressure and vascular collapse [100]. However in later stages the local inflammatory response, described above, could also impact tumor cell capacity for active intravasation via changes in tumor cell gene expression [49] or changes in the microenvironment, that favor tumor cell migration [4] and vascular permeability [101].

\section{Systemic inflammation potentiates tumor cell survival in circulation and extravasation}

Next to CTC release, invasive surgical interventions trigger changes in systemic inflammation that can impact the CTCs ability to survive and extravasate. Extensive evidence has shown that surgical interventions lead to an imbalance of the innate and adaptive immune regulatory mechanisms and impair immune functions [102-105]. One of the effects of surgery is systemic immunosuppression of cells that participate in CTCs clearance $[106,107]$ and in the control of tumor cell dissemination [108, 109]: natural killers (NK) and phagocytic monocytes/macrophages. This process is triggered by the activation of the hypothalamic-pituitary-adrenal axis in response to surgical trauma stress [110, 111]. NK cell numbers and cytotoxic activity experience a rapid and prolonged (up to 10-30 days) decrease due to surgical interventions $[112,113]$. Additionally, monocytes/macrophages phagocytic and chemotactic functions and antigen recognition mechanisms are compromised due to surgery [114, $115]$ and even as a result of anesthesia [116, 117]. Likewise, suppression of NKs and macrophages in a model of hepatic metastasis has shown to potentiate tumor cell uptake and outgrowth in the liver [107].

An increase in neutrophil counts in blood $[118,119]$ is triggered by surgical trauma. As a result, tumor cell survival, via NK cell suppression, is promoted and tumor cell extravasation is stimulated through IL-1 and matrix metalloproteases secretion [120]. Moreover, in response to injury neutrophils expel granule and nuclear constituents (including DNA and histones) mixed with a variety of cytokines, known as neutrophil extracellular traps (NETs) [121]. These structures sequester CTCs [122] from circulation and promote tumor cell invasion and metastatic outgrowth [123]. Post-operative NET formations in a cohort of patients with liver resection for metastatic colorectal cancer were associated with the extent of surgical resection and resulted in an increased risk of recurrence [124]. Indeed, NETs inhibition, described in a murine model of surgical stress, attenuates the development of metastasis triggered by the surgical intervention [124].

Another systemic effect of surgery consists of an acute inflammatory response mediated by the release of inflammatory cytokines into circulation [104]. TNF- $\alpha$ and IL- 1 are some of the earliest and most potent systemic mediators of inflammation known to stimulate tumor cell adhesion [125, 126], invasion [127] and neoangiogenesis [128, 129] and potentiate metastasis formation [130, 131]. In addition to inflammatory cytokines, an increase in pro-angiogenic factors, such as VEGF and angiopoietin-2 in plasma has been reported after distinct surgical interventions [63, 132, 133].

In the peritoneal cavity tumor cell adhesion can be facilitated due to exposure of the extracellular matrix after mesothelial cell detachment in response to surgical trauma [134]. This mechanism of regulation of peritoneal inflammation [135] has been shown to lead to increased tumor cell adhesion in non-traumatized areas of the peritoneal cavity [134].

\section{Secondary site effects of surgery}

\section{Metastatic burden can be potentiated by surgical interventions}

Apart from supporting the establishment of new metastases from CTCs, systemic effects of surgical trauma can potentiate the progression of preexisting metastatic foci and contribute to the creation of so called pre-metastatic niches. Over the last decades, numerous clinical and preclinical 
reports strongly relate surgical interventions such as tumor resection and biopsy with an increased metastatic burden in different types of cancer [6-12]. Different aspects of surgical interventions at the primary site ultimately contribute to tumor outgrowth at distant sites, some of which, such as tumor cell shedding in circulation, extravasation, immune cell modulation and pro-tumoral effects of inflammatory cytokines, have been discussed above. Surgical interventions to the primary tumor also exert direct effects on distant tumors. For instance, biopsy mediated acute inflammatory response promotes an increase in lung metastases, associated with neutrophils recruitment to the metastatic site that could be controlled with anti-inflammatory treatment or IL-6 inhibition [10]. Recruited neutrophils induce metastatic progression thought activation of intracellular growth signaling pathways mediated by Toll-like receptor 9 and NETs [124]. Additionally, Al-Sahaf et al. showed that upon primary tumor resection lung metastasis acquired an invasive and proangiogenic phenotype and increased proliferation [6], indicating that humoral responses to surgical trauma can also directly alter secondary tumor gene expression. Some effects of surgical interventions on tumor progression seem to be unrelated to the primary tumor, but rather a direct consequence of a normal wound healing response. In line with this, a wound to a tumor-free tissue has been shown to elicit systemic factors that promote tumor angiogenesis [136] and proliferation [58].

The potentiation of metastatic progression can also be a consequence of an alteration in the inhibitory control exerted by the primary tumor. The primary tumor secretes factors that control the growth of secondary metastasis; and surgical resection of the primary tumor releases this inhibitory control [137-139]. Regulation of angiogenesis plays a major role in this process. It is thought that both pro-angiogenic factors and inhibitors are secreted into the circulation by primary tumors, however inhibitors are more stable and can exert anti-angiogenic effects on distant micrometastases. As a result of primary tumor removal, angiogenesis inhibitors levels drop, an angiogenic switch takes place at distant tumor sites and gives rise to tumor expansion. Studies done by Folkman have elucidated the molecular mechanisms responsible for this effect with angiostatin and endostatin as main regulators [137-139].

\section{Pre-metastatic niche formation as a consequence of surgery}

Little is known about the effects of surgery on pre-metastatic niche formation. However, the systemic inflammation elicited in response to surgery could also contribute to the alteration of the microenvironment at distant sites and create pre-metastatic niches. In line with this idea hepatic ischemia-reperfusion injury has shown to increase circulating bone marrow-derived progenitor cells accompanied by a marked microvascular density in the liver that resulted in a higher incidence of liver metastases, upon tumor cell injection after injury [140]. Hypoxic conditions at the primary tumor site created by decreased tissue perfusion upon a surgical intervention are also likely to stimulate pre-metastatic niche formation at distant sites [141]. Conditioned medium derived from hypoxic mammary tumor cells has been reported to increase bone marrow-derived cell infiltration into the lung and rise the metastatic burden at this site [142]. Future studies should focus on elucidating the mechanisms that contribute to the formation of premetastatic niches in response to surgical interventions at the primary tumor site.

\section{Prevention of undesired tumor promoting effects of surgical interventions}

Extensive evidence links therapeutic and diagnostic invasive interventions with a stimulation of tumor progression. This does not imply however that the current cancer management protocols should be abandoned, as in most cases they allow for cure or extend lifespan of patients, that otherwise would not be possible. Instead the increasing knowledge of the cellular and molecular mechanisms underlying this phenomenon offer a therapeutic possibility to prevent these adverse effects, making clinical interventions even more beneficial for the patient. Several prevention strategies have been proposed (Fig. 2).

Since immune alteration plays a main role in surgery induced tumor progression perioperative immune-modulators have been proposed to suppress undesired effects of surgery. For example, IL-2 treatment prior to surgery has shown to counteract surgery-induced immunosuppression and extend survival of colorectal cancer patients [143, 144]. Other modulators such as granulocyte macrophage-colony stimulating factor, IFN- $\alpha$ and TNF- $\alpha$ also improved postoperative immune functions [130, 145, 146]. Although IL-2 and IFN- $\alpha$ treatments have shown severe side effects, some recent studies have reported that short-term administration schedules and drug delivery strategies induce only mild sideeffects, suggesting that the use of these therapies should be further investigated to evaluate their potential to safely prevent surgery induced tumor progression [147, 148]. Another prospective strategy aimed to stimulate the adaptive immune response against the remaining tumor cells consists of the use of postoperative dendritic cell vaccines (DCV) [149, 150]. In the last years the optimization of DCV for therapeutic purposes has renewed the interest towards this approach and the number of clinical trials testing DCV is currently rising [151]. 


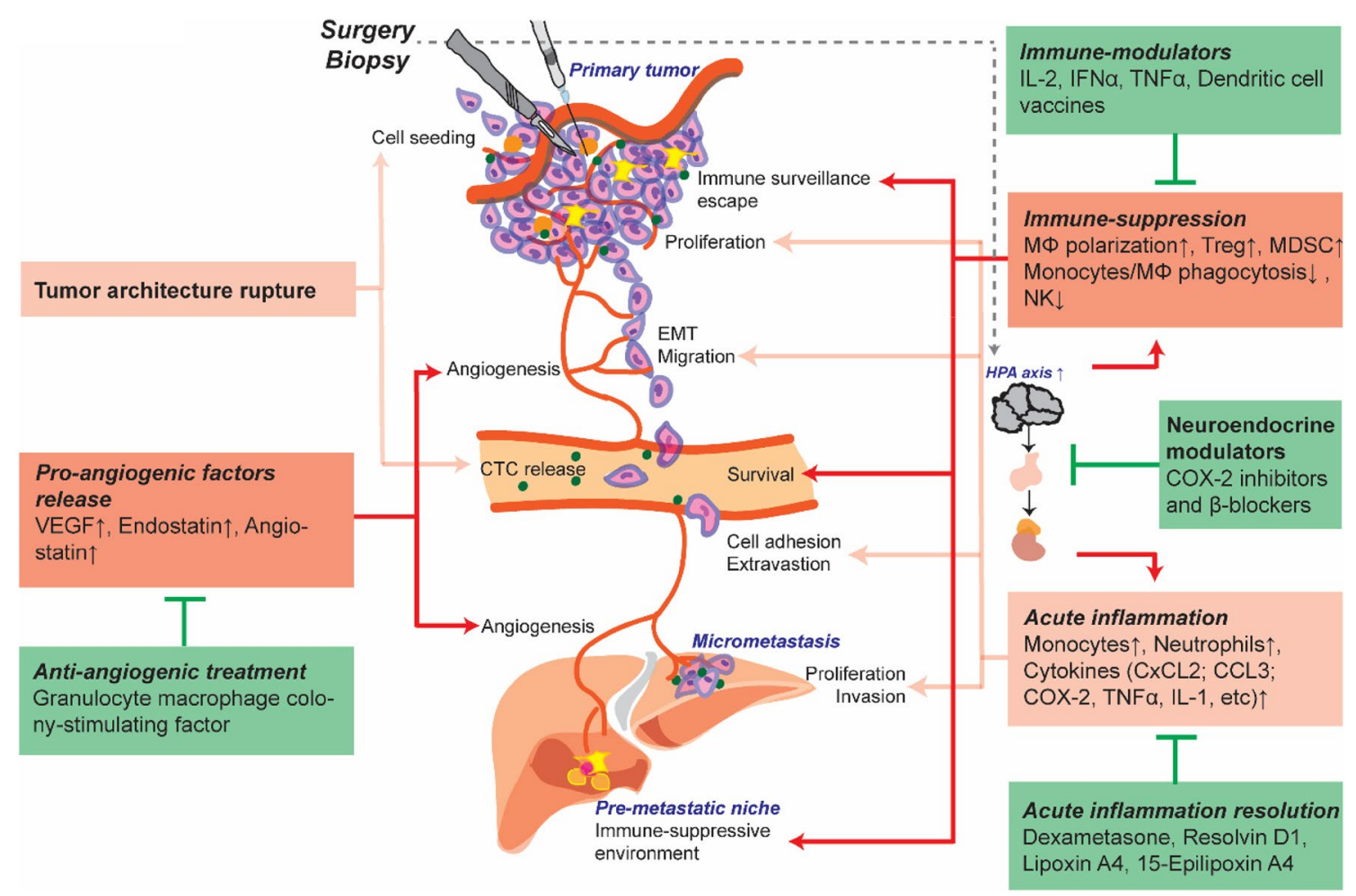

Fig. 2 Surgical procedure impact on tumor cell progression and metastatic spread and prevention strategies. Surgical trauma induced immune-suppression, acute inflammation, pro-angiogenic factors release, and tumor architecture rupture contribute to tumor cell proliferation, migration, EMT; release and survival in circulation; adhesion to the endothelial wall and extravasation; escape of immune surveillance and angiogenic switch. Several therapeutic approaches show potential benefit to prevent these undesired effects: immune and neuroendocrine modulators, mediators of acute inflammation resolution

An alternative approach is to utilize factors that would resolve the acute inflammation that is triggered by surgical procedures [152]. Perioperative treatment with dexamethasone, a potent anti-inflammatory drug, has shown to prevent biopsy-induced tumor cell migration and proliferation by reducing monocytes recruitment to the injured site and reduced growth of biopsied tumors in multifocal glioblastoma patients [4]. Other mediators of inflammation resolution such as Resolvin D1, Lipoxin A4 [153] and 15-Epilipoxin A4 [154] represent a therapeutic potential due to their capacity to attenuate systemic inflammation.

Stress induced by surgery triggers the activation of the hypothalamic-pituitary-adrenal axis that modulates the immune system response via neuroendocrine factors $[110,111]$. Preclinical studies have shown that perioperative blockade of neuroendocrine factors by COX-2 inhibitors and $\beta$-blockers can prevent immune suppression and decrease surgery-induced local tumor growth and metastatic progression $[155,156]$. This notion has been supported by recent clinical data that report, not only the safe use of and anti-angiogenic treatments. $I L-2$ interleukin $2, I F N \alpha$ interferon alpha, $T N F \alpha$ tumor necrosis factor alpha, $M \Phi$ macrophages, Treg regulatory T cell, $M D S C$ myeloid-derived suppressor cell, $N K$ natural killer, $C O X-2$ cyclooxygenase $2, C x C L 2$ chemokine $(\mathrm{C}-\mathrm{X}-\mathrm{C}$ motif) ligand 2, CCL3 chemokine (C-C motif) ligand 3, IL-1 interleukin 1, $V E G F$ vascular endothelial growth factor, $E M T$ epithelial-mesenchymal transition, CTC circulating tumor cell, HPA hypothalamic-pituitary-adrenal

these treatments in patients, but also their efficacy to inhibit inflammatory ligands (IL-6, C-reactive protein), preserve the levels of cytokines that enhance anti-tumor activity by NK and cytotoxic T cells (IL-12, IFN- $\gamma$ ), decrease tumor infiltration with pro-inflammatory monocytes and abrogate the activity of immune suppressive CD4 T cells $[157,158]$. Importantly, in the excised tumor preoperative treatment showed to suppress molecular pathways related to metastatic progression [157]. Although the impact of these treatments on long-term clinical outcome after surgery still needs to be assessed, the potential benefit of this approach is supported by studies that show association between the use of COX-2 inhibitors and $\beta$-blockers with progression-free survival in breast cancer patients $[159,160]$.

Tumor growth inhibition with preoperative [161, 162] or directly postoperative [163] chemotherapy or antiangiogenic [164] treatments has previously been studied and although in some cases these therapies have shown to improve long term-survival [165] their use remains controversial. This is due not only to other studies where 
chemotherapy showed no benefit [166], but also because in some cases it seemed to elicit unwanted effects, similar to surgical trauma, that can contribute to tumor progression and spreading [167]. Moreover the adverse side effects of chemotherapy such as a strong inflammatory response and impaired wound healing constitute an additional challenge for their wide use in the clinic.

\section{Concluding remarks}

Clinical and preclinical evidence indicate that both biopsies and tumor resections can have multiple effects that stimulate tumor progression, metastatic spreading and outgrowth. However, given the variety of surgical procedures, tumor types and stages that are encountered in the clinical practice, the conclusions drawn from these studies cannot be generalized. For instance, in early stage tumors, surgical procedures might have no impact on tumor progression because tumor cells still lack the genetic makeup necessary to acquire malignant features when a pro-inflammatory microenvironment is induced [61].

Moreover, the benefit of these surgical procedures for appropriate diagnosis and extended survival is undeniable and outweighs the potential negative effects, advocating against their discontinuation. Instead, the described findings show the importance of future studies addressed to further elucidate the cellular and molecular mechanisms behind these processes. This will allow to develop novel approaches to mitigate the local and systemic undesired effects of surgical interventions and even further improve the clinical benefit of these procedures.

Acknowledgements This work was financially supported by European Research Council Grant CANCER-RECURRENCE 648804 (to J.v.R.), the CancerGenomics.nl (Netherlands Organisation for Scientific Research) program (to J.v.R.), the Doctor Josef Steiner Foundation (to J.v.R) and the European Union's Horizon 2020 research and innovation program under the Marie Sklodowska-Curie grant agreement No 642866 (to J.v.R).

Open Access This article is distributed under the terms of the Creative Commons Attribution 4.0 International License (http://creativeco mmons.org/licenses/by/4.0/), which permits unrestricted use, distribution, and reproduction in any medium, provided you give appropriate credit to the original author(s) and the source, provide a link to the Creative Commons license, and indicate if changes were made.

\section{References}

1. McCutcheon BA et al (2016) Predictors of surgical site infection following craniotomy for intracranial neoplasms: an analysis of prospectively collected data in the American College of Surgeons National Surgical Quality Improvement Program Database.
World Neurosurg 88:350-358. https://doi.org/10.1016/j. wneu.2015.12.068

2. Cote DJ, Dubois HM, Karhade AV, Smith TR (2016) Venous thromboembolism in patients undergoing craniotomy for brain tumors: a U.S. nationwide analysis. Semin Thromb Hemost 42:870-876. https://doi.org/10.1055/s-0036-1592306

3. Senders JT et al (2018) Venous thromboembolism and intracranial hemorrhage after craniotomy for primary malignant brain tumors: a National Surgical Quality Improvement Program analysis. J Neurooncol 136:135-145. https://doi.org/10.1007/ s11060-017-2631-5

4. Alieva $\mathrm{M}$ et al (2017) Preventing inflammation inhibits biopsymediated changes in tumor cell behavior. Sci Rep 7:7529. https ://doi.org/10.1038/s41598-017-07660-4

5. Tagliabue E et al (2003) Role of HER2 in wound-induced breast carcinoma proliferation. Lancet 362:527-533. https:// doi.org/10.1016/S0140-6736(03)14112-8

6. Al-Sahaf O, Wang JH, Browne TJ, Cotter TG, Redmond HP (2010) Surgical injury enhances the expression of genes that mediate breast cancer metastasis to the lung. Ann Surg 252:1037-1043. https://doi.org/10.1097/SLA.0b013e3181 efc635

7. Bogden AE, Moreau JP, Eden PA (1997) Proliferative response of human and animal tumours to surgical wounding of normal tissues: onset, duration and inhibition. Br J Cancer 75:1021-1027

8. Estourgie SH, Nieweg OE, Kroon BB (2004) High incidence of in-transit metastases after sentinel node biopsy in patients with melanoma. Br J Surg 91:1370-1371. https://doi.org/10.1002/ bjs. 4692

9. Hansen NM, Ye X, Grube BJ, Giuliano AE (2004) Manipulation of the primary breast tumor and the incidence of sentinel node metastases from invasive breast cancer. Arch Surg 139:634-639. https://doi.org/10.1001/archsurg.139.6.634 (discussion 639-640)

10. Hobson $\mathbf{J}$ et al (2013) Acute inflammation induced by the biopsy of mouse mammary tumors promotes the development of metastasis. Breast Cancer Res Treat 139:391-401. https://doi. org/10.1007/s10549-013-2575-1

11. Lange PH, Hekmat K, Bosl G, Kennedy BJ, Fraley EE (1980) Acclerated growth of testicular cancer after cytoreductive surgery. Cancer 45:1498-1506

12. Peeters CF, de Waal RM, Wobbes T, Westphal JR, Ruers TJ (2006) Outgrowth of human liver metastases after resection of the primary colorectal tumor: a shift in the balance between apoptosis and proliferation. Int J Cancer 119:1249-1253. https ://doi.org/10.1002/ijc. 21928

13. Stroncek JD, Reichert WM (2008) Overview of wound healing in different tissue types. In: Reichert WM (ed) Indwelling neural implants: strategies for contending with the in vivo environment. Taylor \& Francis, Boca Raton

14. Sakurai M, Okamura J, Seki K, Kuroda C (1983) Needle tract implantation of hepatocellular carcinoma after percutaneous liver biopsy. Am J Surg Pathol 7:191-195

15. Lundstedt C, Stridbeck H, Andersson R, Tranberg KG, AndrenSandberg A (1991) Tumor seeding occurring after fine-needle biopsy of abdominal malignancies. Acta Radiol 32:518-520

16. Shyamala K, Girish HC, Murgod S (2014) Risk of tumor cell seeding through biopsy and aspiration cytology. J Int Soc Prev Community Dent 4:5-11. https://doi.org/10.4103/22310762.129446

17. Diaz LK, Wiley EL, Venta LA (1999) Are malignant cells displaced by large-gauge needle core biopsy of the breast? AJR Am J Roentgenol 173:1303-1313. https://doi.org/10.2214/ ajr.173.5.10541110

18. Pierallini A et al (1999) Metastasis along the stereotactic biopsy trajectory in glioblastoma multiforme. Acta Neurochir (Wien) 141:1011-1012 
19. Steinmetz MP, Barnett GH, Kim BS, Chidel MA, Suh JH (2001) Metastatic seeding of the stereotactic biopsy tract in glioblastoma multiforme: case report and review of the literature. J Neurooncol 55:167-171

20. Karlsson B, Ericson K, Kihlstrom L, Grane P (1997) Tumor seeding following stereotactic biopsy of brain metastases. Report of two cases. J Neurosurg 87:327-330. https://doi.org/10.3171/ jns.1997.87.2.0327

21. Pinggera D et al (2017) Serious tumor seeding after brainstem biopsy and its treatment-a case report and review of the literature. Acta Neurochir (Wien) 159:751-754. https://doi.org/10.1007/ s00701-017-3102-7

22. Silva MA et al (2008) Needle track seeding following biopsy of liver lesions in the diagnosis of hepatocellular cancer: a systematic review and meta-analysis. Gut 57:1592-1596. https://doi. org/10.1136/gut.2008.149062

23. Karwowski JK, Nowels KW, McDougall IR, Weigel RJ (2002) Needle track seeding of papillary thyroid carcinoma from fine needle aspiration biopsy. A case report. Acta Cytol 46:591-595. https://doi.org/10.1159/000326884

24. Warshaw AL (1991) Implications of peritoneal cytology for staging of early pancreatic cancer. Am J Surg 161:26-29 (discussion 29-30)

25. Leach SD et al (1995) Significance of peritoneal cytology in patients with potentially resectable adenocarcinoma of the pancreatic head. Surgery 118:472-478

26. Chang KJ (1995) Endoscopic ultrasound-guided fine needle aspiration in the diagnosis and staging of pancreatic tumors. Gastrointest Endosc Clin N Am 5:723-734

27. Wilkinson MJ et al (2015) Percutaneous core needle biopsy in retroperitoneal sarcomas does not influence local recurrence or overall survival. Ann Surg Oncol 22:853-858. https://doi. org/10.1245/s10434-014-4059-x

28. Hwang SY et al (2016) Safety and accuracy of core biopsy in retroperitoneal sarcomas. Asia Pac J Clin Oncol 12:e174-178. https://doi.org/10.1111/ajco.12125

29. Berger-Richardson D, Swallow CJ (2017) Needle tract seeding after percutaneous biopsy of sarcoma: risk/benefit considerations. Cancer 123:560-567. https://doi.org/10.1002/cncr.30370

30. Michalopoulos NV et al (2008) Needle tract seeding after vacuum-assisted breast biopsy. Acta Radiol 49:267-270. https://doi. org/10.1080/02841850701775030

31. Fernandes Cabral DT, Zenonos GA, Fernandez-Miranda JC, Wang EW, Gardner PA (2017) Iatrogenic seeding of skull base chordoma following endoscopic endonasal surgery. J Neurosurg. https://doi.org/10.3171/2017.6.JNS17111

32. Farias JA, Laryea J, Gokden N, Kamel MH (2016) Peritoneal seeding following incomplete resection of mixed epithelial stromal tumor of the kidney: first case report. Urol Ann 8:114-117. https://doi.org/10.4103/0974-7796.171493

33. Ahn JH et al (2012) Risk for leptomeningeal seeding after resection for brain metastases: implication of tumor location with mode of resection. J Neurosurg 116:984-993. https://doi. org/10.3171/2012.1.JNS111560

34. Ma R et al (2018) Risk of leptomeningeal carcinomatosis in patients with brain metastases treated with stereotactic radiosurgery. J Neurooncol 136:395-401. https://doi.org/10.1007/s1106 0-017-2666-7

35. Lee SD et al (2013) Laparoscopic versus open surgery for stage I rectal cancer: long-term oncologic outcomes. World J Surg 37:646-651. https://doi.org/10.1007/s00268-012-1846-z

36. Tsivian A, Sidi AA (2003) Port site metastases in urological laparoscopic surgery. J Urol 169:1213-1218. https://doi. org/10.1097/01.ju.0000035910.75480.4b

37. Vergote I, Marquette S, Amant F, Berteloot P, Neven P (2005) Port-site metastases after open laparoscopy: a study in 173 patients with advanced ovarian carcinoma. Int J Gynecol Cancer 15:776-779. https://doi.org/10.1111/j.1525-1438.2005.00135.x

38. Peng $\mathrm{Y}$ et al (2017) Inhibition of peritoneal dissemination of colon cancer by hyperthermic $\mathrm{CO}_{2}$ insufflation: a novel approach to prevent intraperitoneal tumor spread. PLoS ONE 12:e172097. https://doi.org/10.1371/journal.pone.0172097

39. Peng $\mathrm{Y}$ et al (2009) Heated and humidified $\mathrm{CO}_{2}$ prevents hypothermia, peritoneal injury, and intra-abdominal adhesions during prolonged laparoscopic insufflations. J Surg Res 151:40-47. https ://doi.org/10.1016/j.jss.2008.03.039

40. Rosario MT et al (2006) Does $\mathrm{CO}_{2}$ pneumoperitoneum alter the ultra-structuture of the mesothelium? J Surg Res 133:84-88. https://doi.org/10.1016/j.jss.2005.09.032

41. van den Tol PM et al (1998) Reduction of peritoneal trauma by using nonsurgical gauze leads to less implantation metastasis of spilled tumor cells. Ann Surg 227:242-248

42. Mathew G et al (1996) Wound metastases following laparoscopic and open surgery for abdominal cancer in a rat model. Br J Surg 83:1087-1090

43. Mutter D et al (1999) Increased tumor growth and spread after laparoscopy vs laparotomy: influence of tumor manipulation in a rat model. Surg Endosc 13:365-370

44. Iwamura M et al (2004) Port site recurrence of renal cell carcinoma following retroperitoneoscopic radical nephrectomy with manual extraction without using entrapment sac or wound protector. J Urol 171:1234-1235. https://doi.org/10.1097/01. ju.0000110611.55559.f3

45. Carpinteri $\mathrm{S}$ et al (2015) Peritoneal tumorigenesis and inflammation are ameliorated by humidified-warm carbon dioxide insufflation in the mouse. Ann Surg Oncol 22(Suppl 3):1540 1547. https://doi.org/10.1245/s10434-015-4508-1

46. Lee SW, Gleason NR, Bessler M, Whelan RL (2000) Port site tumor recurrence rates in a murine model of laparoscopic splenectomy decreased with increased experience. Surg Endosc $14: 805-811$

47. Quail DF, Joyce JA (2013) Microenvironmental regulation of tumor progression and metastasis. Nat Med 19:1423-1437. https://doi.org/10.1038/nm.3394

48. Kitamura T, Qian BZ, Pollard JW (2015) Immune cell promotion of metastasis. Nat Rev Immunol 15:73-86. https://doi. org/10.1038/nri3789

49. Mathenge EG et al (2014) Core needle biopsy of breast cancer tumors increases distant metastases in a mouse model. Neoplasia 16:950-960. https://doi.org/10.1016/j.neo.2014.09.004

50. Predina J et al (2013) Changes in the local tumor microenvironment in recurrent cancers may explain the failure of vaccines after surgery. Proc Natl Acad Sci USA 110:E415-E424. https ://doi.org/10.1073/pnas.1211850110

51. Weber $\mathrm{M}$ et al (2015) Macrophage polarisation changes within the time between diagnostic biopsy and tumour resection in oral squamous cell carcinomas-an immunohistochemical study. Br J Cancer 113:510-519. https://doi.org/10.1038/ bjc.2015.212

52. Luna-More S, Florez P, Ayala A, Diaz F, Santos A (1997) Neutral and acid mucins and eosinophil and argyrophil crystalloids in carcinoma and atypical adenomatous hyperplasia of the prostate. Pathol Res Pract 193:291-298. https://doi.org/10.1016/S0344 -0338(97)80006-4

53. Ishibashi $\mathrm{S}$ et al (2006) Tumor-associated tissue eosinophilia in human esophageal squamous cell carcinoma. Anticancer Res 26:1419-1424

54. da Silva JM et al (2014) Eosinophil depletion protects mice from tongue squamous cell carcinoma induced by 4-nitroquinoline1-oxide. Histol Histopathol 29:387-396. https://doi.org/10.14670 /HH-29.387 
55. von Wasielewski R et al (2000) Tissue eosinophilia correlates strongly with poor prognosis in nodular sclerosing Hodgkin's disease, allowing for known prognostic factors. Blood 95:1207-1213

56. Szalayova $\mathrm{G}$ et al (2016) Human breast cancer biopsies induce eosinophil recruitment and enhance adjacent cancer cell proliferation. Breast Cancer Res Treat 157:461-474. https://doi. org/10.1007/s10549-016-3839-3

57. Eming SA, Krieg T, Davidson JM (2007) Inflammation in wound repair: molecular and cellular mechanisms. J Investig Dermatol 127:514-525. https://doi.org/10.1038/sj.jid.5700701

58. Abramovitch R, Marikovsky M, Meir G, Neeman M (1999) Stimulation of tumour growth by wound-derived growth factors. Br J Cancer 79:1392-1398. https://doi.org/10.1038/sj.bjc.6690223

59. Hofer SO, Shrayer D, Reichner JS, Hoekstra HJ, Wanebo HJ (1998) Wound-induced tumor progression: a probable role in recurrence after tumor resection. Arch Surg 133:383-389

60. Okolie $\mathrm{O}$ et al (2016) Reactive astrocytes potentiate tumor aggressiveness in a murine glioma resection and recurrence model. Neuro Oncol 18:1622-1633. https://doi.org/10.1093/ neuonc/now 117

61. Chen X et al (2015) Surgery time interval and molecular subtype may influence Ki67 change after core needle biopsy in breast cancer patients. BMC Cancer 15:822. https://doi.org/10.1186/ s12885-015-1853-1

62. Wu FP, Hoekman K, Meijer S, Cuesta MA (2003) VEGF and endostatin levels in wound fluid and plasma after breast surgery. Angiogenesis 6:255-257. https://doi.org/10.1023/ B:AGEN.0000029410.32264.b0

63. Hormbrey E, Han C, Roberts A, McGrouther DA, Harris AL (2003) The relationship of human wound vascular endothelial growth factor (VEGF) after breast cancer surgery to circulating VEGF and angiogenesis. Clin Cancer Res 9:4332-4339

64. Barbero $\mathrm{S}$ et al (2003) Stromal cell-derived factor 1alpha stimulates human glioblastoma cell growth through the activation of both extracellular signal-regulated kinases $1 / 2$ and Akt. Cancer Res 63:1969-1974

65. O'Brien ER, Howarth C, Sibson NR (2013) The role of astrocytes in CNS tumors: pre-clinical models and novel imaging approaches. Front Cell Neurosci 7:40. https://doi.org/10.3389/ fncel.2013.00040

66. Weil S et al (2017) Tumor microtubes convey resistance to surgical lesions and chemotherapy in gliomas. Neuro Oncol 19:13161326. https://doi.org/10.1093/neuonc/nox070

67. Friedl P, Wolf K (2003) Tumour-cell invasion and migration: diversity and escape mechanisms. Nat Rev Cancer 3:362-374. https://doi.org/10.1038/nrc1075

68. Condeelis J, Pollard JW (2006) Macrophages: obligate partners for tumor cell migration, invasion, and metastasis. Cell 124:263266. https://doi.org/10.1016/j.cell.2006.01.007

69. Beerling E et al (2016) Plasticity between epithelial and mesenchymal states unlinks emt from metastasis-enhancing stem cell capacity. Cell Rep 14:2281-2288. https://doi.org/10.1016/j.celre p.2016.02.034

70. Parsa AT et al (2005) Prognostic significance of intracranial dissemination of glioblastoma multiforme in adults. J Neurosurg 102:622-628. https://doi.org/10.3171/jns.2005.102.4.0622

71. Wijnenga MMJ et al (2017) Does early resection of presumed low-grade glioma improve survival? A clinical perspective. J Neurooncol 133:137-146. https://doi.org/10.1007/s1106 0-017-2418-8

72. Hoelzinger DB, Demuth T, Berens ME (2007) Autocrine factors that sustain glioma invasion and paracrine biology in the brain microenvironment. J Natl Cancer Inst 99:1583-1593. https://doi. org/10.1093/jnci/djm187
73. Liu L et al (2010) Astrocyte elevated gene-1 upregulates matrix metalloproteinase- 9 and induces human glioma invasion. Cancer Res 70:3750-3759. https://doi.org/10.1158/0008-5472. CAN-09-3838

74. Le DM et al (2003) Exploitation of astrocytes by glioma cells to facilitate invasiveness: a mechanism involving matrix metalloproteinase- 2 and the urokinase-type plasminogen activatorplasmin cascade. J Neurosci 23:4034-4043

75. Alieva M, Ritsma L, Giedt RJ, Weissleder R, van Rheenen J (2014) Imaging windows for long-term intravital imaging: general overview and technical insights. Intravital 3:e29917. https ://doi.org/10.4161/intv.29917

76. Kessenbrock K, Plaks V, Werb Z (2010) Matrix metalloproteinases: regulators of the tumor microenvironment. Cell 141:52-67. https://doi.org/10.1016/j.cell.2010.03.015

77. Hagemann T et al (2004) Enhanced invasiveness of breast cancer cell lines upon co-cultivation with macrophages is due to TNFalpha dependent up-regulation of matrix metalloproteases. Carcinogenesis 25:1543-1549. https://doi.org/10.1093/carcin/bgh14 6

78. Du R et al (2008) HIF1alpha induces the recruitment of bone marrow-derived vascular modulatory cells to regulate tumor angiogenesis and invasion. Cancer Cell 13:206-220. https://doi. org/10.1016/j.ccr.2008.01.034

79. Massague J (2008) TGFbeta in cancer. Cell 134:215-230. https ://doi.org/10.1016/j.cell.2008.07.001

80. Wyckoff J et al (2004) A paracrine loop between tumor cells and macrophages is required for tumor cell migration in mammary tumors. Cancer Res 64:7022-7029. https://doi.org/10.1158/00085472.CAN-04-1449

81. O'Sullivan C, Lewis CE, Harris AL, McGee JO (1993) Secretion of epidermal growth factor by macrophages associated with breast carcinoma. Lancet 342:148-149

82. Lewis C, Murdoch C (2005) Macrophage responses to hypoxia: implications for tumor progression and anti-cancer therapies. Am J Pathol 167:627-635. https://doi.org/10.1016/S0002 -9440(10)62038-X

83. Osswald $\mathrm{M}$ et al (2015) Brain tumour cells interconnect to a functional and resistant network. Nature 528:93-98. https://doi. org/10.1038/nature 16071

84. Steeg PS (2016) Targeting metastasis. Nat Rev Cancer 16:201218. https://doi.org/10.1038/nrc.2016.25

85. Cristofanilli $\mathrm{M}$ et al (2004) Circulating tumor cells, disease progression, and survival in metastatic breast cancer. N Engl J Med 351:781-791. https://doi.org/10.1056/NEJMoa040766

86. Pantel K, Brakenhoff RH, Brandt B (2008) Detection, clinical relevance and specific biological properties of disseminating tumour cells. Nat Rev Cancer 8:329-340. https://doi.org/10.1038/nrc23 75

87. Kusukawa $\mathbf{J}$ et al (2000) Dissemination of cancer cells into circulation occurs by incisional biopsy of oral squamous cell carcinoma. J Oral Pathol Med 29:303-307

88. Hu XC, Chow LW (2000) Fine needle aspiration may shed breast cells into peripheral blood as determined by RT-PCR. Oncology 59:217-222. https://doi.org/10.1159/000012164

89. Louha $\mathrm{M}$ et al (1999) Liver resection and needle liver biopsy cause hematogenous dissemination of liver cells. Hepatology 29:879-882. https://doi.org/10.1002/hep.510290348

90. Yamaguchi K, Takagi Y, Aoki S, Futamura M, Saji S (2000) Significant detection of circulating cancer cells in the blood by reverse transcriptase-polymerase chain reaction during colorectal cancer resection. Ann Surg 232:58-65

91. Papavasiliou P, Fisher T, Kuhn J, Nemunaitis J, Lamont J (2010) Circulating tumor cells in patients undergoing surgery for hepatic metastases from colorectal cancer. Proc (Bayl Univ Med Cent) 23:11-14 
92. Pesta M, Fichtl J, Kulda V, Topolcan O, Treska V (2013) Monitoring of circulating tumor cells in patients undergoing surgery for hepatic metastases from colorectal cancer. Anticancer Res 33:2239-2243

93. Juratli MA et al (2015) In vivo long-term monitoring of circulating tumor cells fluctuation during medical interventions. PLoS ONE 10:e0137613. https://doi.org/10.1371/journal.pone.01376 13

94. Juratli MA et al (2014) Real-time monitoring of circulating tumor cell release during tumor manipulation using in vivo photoacoustic and fluorescent flow cytometry. Head Neck 36:1207-1215. https://doi.org/10.1002/hed.23439

95. Sandri MT et al (2010) Changes in circulating tumor cell detection in patients with localized breast cancer before and after surgery. Ann Surg Oncol 17:1539-1545. https://doi.org/10.1245/ s10434-010-0918-2

96. van Dalum $\mathrm{G}$ et al (2015) Circulating tumor cells before and during follow-up after breast cancer surgery. Int J Oncol 46:407413. https://doi.org/10.3892/ijo.2014.2694

97. Markar SR et al (2016) Significance of microscopically incomplete resection margin after esophagectomy for esophageal cancer. Ann Surg 263:712-718. https://doi.org/10.1097/SLA.00000 00000001325

98. Rickles AS et al (2015) High rate of positive circumferential resection margins following rectal cancer surgery: a call to action. Ann Surg 262:891-898. https://doi.org/10.1097/ SLA.0000000000001391

99. Marchegiani G et al (2015) Patterns of recurrence after resection of IPMN: who, when, and how? Ann Surg 262:1108-1114. https ://doi.org/10.1097/SLA.0000000000001008

100. Bockhorn M, Jain RK, Munn LL (2007) Active versus passive mechanisms in metastasis: do cancer cells crawl into vessels, or are they pushed? Lancet Oncol 8:444-448. https://doi. org/10.1016/S1470-2045(07)70140-7

101. Harney AS et al (2015) Real-time imaging reveals local, transient vascular permeability, and tumor cell intravasation stimulated by TIE2hi macrophage-derived VEGFA. Cancer Discov 5:932-943. https://doi.org/10.1158/2159-8290.CD-15-0012

102. Angele MK, Chaudry IH (2005) Surgical trauma and immunosuppression: pathophysiology and potential immunomodulatory approaches. Langenbecks Arch Surg 390:333-341. https://doi. org/10.1007/s00423-005-0557-4

103. Ni Choileain N, Redmond HP (2006) Cell response to surgery. Arch Surg 141:1132-1140. https://doi.org/10.1001/archs urg. 141.11.1132

104. Lin E, Calvano SE, Lowry SF (2000) Inflammatory cytokines and cell response in surgery. Surgery 127:117-126. https://doi. org/10.1067/msy.2000.101584

105. Hogan BV, Peter MB, Shenoy HG, Horgan K, Hughes TA (2011) Surgery induced immunosuppression. Surgeon 9:38-43. https:// doi.org/10.1016/j.surge.2010.07.011

106. Riccardi C, Santoni A, Barlozzari T, Puccetti P, Herberman RB (1980) In vivo natural reactivity of mice against tumor cells. Int J Cancer 25:475-486

107. Rushfeldt C, Sveinbjornsson B, Seljelid R, Smedsrod B (1999) Early events of hepatic metastasis formation in mice: role of Kupffer and NK-cells in natural and interferon-gamma-stimulated defense. J Surg Res 82:209-215. https://doi.org/10.1006/ jsre.1998.5532

108. Heuff $\mathrm{G}$ et al (1993) Enhanced tumour growth in the rat liver after selective elimination of Kupffer cells. Cancer Immunol Immunother 37:125-130

109. Bayon LG et al (1996) Role of Kupffer cells in arresting circulating tumor cells and controlling metastatic growth in the liver.
Hepatology 23:1224-1231. https://doi.org/10.1002/hep.51023 0542

110. Chrousos GP (1995) The hypothalamic-pituitary-adrenal axis and immune-mediated inflammation. N Engl J Med 332:1351-1362. https://doi.org/10.1056/NEJM199505183322008

111. Kimura F, Shimizu H, Yoshidome H, Ohtsuka M, Miyazaki M (2010) Immunosuppression following surgical and traumatic injury. Surg Today 40:793-808. https://doi.org/10.1007/s0059 5-010-4323-z

112. Cristaldi $\mathrm{M}$ et al (1997) Lymphocytic subpopulation changes after open and laparoscopic cholecystectomy: a prospective and comparative study on 38 patients. Surg Laparosc Endosc $7: 255-261$

113. Lennard TW et al (1985) The influence of surgical operations on components of the human immune system. Br J Surg 72:771-776

114. Brune IB et al (1998) Normal T lymphocyte and monocyte function after minimally invasive surgery. Surg Endosc 12:1020-1024

115. Sietses C et al (1999) A prospective randomized study of the systemic immune response after laparoscopic and conventional Nissen fundoplication. Surgery 126:5-9. https://doi.org/10.1067/ msy. 1999.98702

116. Wu GJ et al (2005) Propofol specifically inhibits mitochondrial membrane potential but not complex I NADH dehydrogenase activity, thus reducing cellular ATP biosynthesis and migration of macrophages. Ann N Y Acad Sci 1042:168-176. https://doi. org/10.1196/annals.1338.019

117. Chen RM et al (2003) Propofol suppresses macrophage functions and modulates mitochondrial membrane potential and cellular adenosine triphosphate synthesis. Anesthesiology 98:1178-1185

118. Cook EJ et al (2007) Post-operative neutrophil-lymphocyte ratio predicts complications following colorectal surgery. Int J Surg 5:27-30. https://doi.org/10.1016/j.ijsu.2006.05.013

119. Tabuchi Y, Shinka S, Ishida H (1989) The effects of anesthesia and surgery on count and function of neutrophils. J Anesth 3:123-131. https://doi.org/10.1007/s0054090030123

120. Spiegel A et al (2016) Neutrophils suppress intraluminal NK cell-mediated tumor cell clearance and enhance extravasation of disseminated carcinoma cells. Cancer Discov 6:630-649. https ://doi.org/10.1158/2159-8290.CD-15-1157

121. Brinkmann V et al (2004) Neutrophil extracellular traps kill bacteria. Science 303:1532-1535. https://doi.org/10.1126/scien ce. 1092385

122. Cools-Lartigue $\mathbf{J}$ et al (2013) Neutrophil extracellular traps sequester circulating tumor cells and promote metastasis. J Clin Investig. https://doi.org/10.1172/JCI67484

123. Park J et al (2016) Cancer cells induce metastasis-supporting neutrophil extracellular DNA traps. Sci Transl Med 8:361ra138. https://doi.org/10.1126/scitranslmed.aag1711

124. Tohme $\mathrm{S}$ et al (2016) Neutrophil extracellular traps promote the development and progression of liver metastases after surgical stress. Cancer Res 76:1367-1380. https://doi.org/10.1158/00085472.CAN-15-1591

125. Sawai $\mathrm{H}$ et al (2003) Interleukin-1alpha enhances integrin alpha(6)beta(1) expression and metastatic capability of human pancreatic cancer. Oncology 65:167-173. https://doi. org/10.1159/000072343

126. Mackay F, Loetscher H, Stueber D, Gehr G, Lesslauer W (1993) Tumor necrosis factor alpha (TNF-alpha)-induced cell adhesion to human endothelial cells is under dominant control of one TNF receptor type, TNF-R55. J Exp Med 177:1277-1286

127. Bates RC, Mercurio AM (2003) Tumor necrosis factor-alpha stimulates the epithelial-to-mesenchymal transition of human colonic organoids. Mol Biol Cell 14:1790-1800. https://doi. org/10.1091/mbc.E02-09-0583 
128. Voronov E et al (2003) IL-1 is required for tumor invasiveness and angiogenesis. Proc Natl Acad Sci USA 100:2645-2650. https ://doi.org/10.1073/pnas.0437939100

129. Jing $Y$ et al (2011) Tumor necrosis factor-alpha promotes tumor growth by inducing vascular endothelial growth factor. Cancer Investig 29:485-493. https://doi.org/10.3109/07357 907.2011.597812

130. Sturm JW et al (2003) Influence of TNFA on the formation of liver metastases in a syngenic mouse model. Int J Cancer 107:1121. https://doi.org/10.1002/ijc. 11320

131. Yano S et al (2003) Multifunctional interleukin-1beta promotes metastasis of human lung cancer cells in SCID mice via enhanced expression of adhesion-, invasion- and angiogenesisrelated molecules. Cancer Sci 94:244-252

132. Belizon A et al (2006) Major abdominal surgery increases plasma levels of vascular endothelial growth factor: open more so than minimally invasive methods. Ann Surg 244:792-798. https://doi.org/10.1097/01.sla.0000225272.52313.e2

133. Shantha Kumara HM et al (2009) Colorectal resection, both open and laparoscopic-assisted, in patients with benign indications is associated with proangiogenic changes in plasma angiopoietin 1 and 2 levels. Surg Endosc 23:409-415. https:// doi.org/10.1007/s00464-008-0132-5

134. Oosterling SJ et al (2008) Anti-beta1 integrin antibody reduces surgery-induced adhesion of colon carcinoma cells to traumatized peritoneal surfaces. Ann Surg 247:85-94. https://doi. org/10.1097/SLA.0b013e3181588583

135. Yung S, Chan TM (2009) Intrinsic cells: mesothelial cellscentral players in regulating inflammation and resolution. Perit Dial Int 29(Suppl 2):S21-S27

136. Abramovitch R, Marikovsky M, Meir G, Neeman M (1998) Stimulation of tumour angiogenesis by proximal wounds: spatial and temporal analysis by MRI. Br J Cancer 77:440-447

137. O'Reilly MS et al (1997) Endostatin: an endogenous inhibitor of angiogenesis and tumor growth. Cell 88:277-285

138. O'Reilly MS et al (1994) Angiostatin: a novel angiogenesis inhibitor that mediates the suppression of metastases by a Lewis lung carcinoma. Cell 79:315-328

139. Holmgren L, O'Reilly MS, Folkman J (1995) Dormancy of micrometastases: balanced proliferation and apoptosis in the presence of angiogenesis suppression. Nat Med 1:149-153

140. Lim C et al (2013) Hepatic ischemia-reperfusion increases circulating bone marrow-derived progenitor cells and tumor growth in a mouse model of colorectal liver metastases. J Surg Res 184:888-897. https://doi.org/10.1016/j.jss.2013.04.069

141. Govaert KM et al (2014) Hypoxia after liver surgery imposes an aggressive cancer stem cell phenotype on residual tumor cells. Ann Surg 259:750-759. https://doi.org/10.1097/ SLA.0b013e318295c160

142. Sceneay J et al (2012) Primary tumor hypoxia recruits CD11b+/Ly6Cmed/Ly6G+ immune suppressor cells and compromises NK cell cytotoxicity in the premetastatic niche. Cancer Res 72:3906-3911. https://doi.org/10.1158/0008-5472. CAN-11-3873

143. Brivio F et al (1996) Preoperative interleukin-2 subcutaneous immunotherapy may prolong the survival time in advanced colorectal cancer patients. Oncology 53:263-268

144. Brivio $\mathrm{F}$ et al (2002) Effects of IL-2 preoperative immunotherapy on surgery-induced changes in angiogenic regulation and its prevention of VEGF increase and IL-12 decline. Hepatogastroenterology 49:385-387

145. Oosterling SJ et al (2006) Preoperative granulocyte/macrophage colony-stimulating factor (GM-CSF) increases hepatic dendritic cell numbers and clustering with lymphocytes in colorectal cancer patients. Immunobiology 211:641-649. https ://doi.org/10.1016/j.imbio.2006.06.010
146. Kutza J, Gratz I, Afshar M, Murasko DM (1997) The effects of general anesthesia and surgery on basal and interferon stimulated natural killer cell activity of humans. Anesth Analg 85:918-923

147. Liu G et al (2012) Effective modulation of CD4(+)CD25 (+ high) regulatory $\mathrm{T}$ and NK cells in malignant patients by combination of interferon-alpha and interleukin-2. Cancer Immunol Immunother 61:2357-2366. https://doi.org/10.1007/s0026 2-012-1297-2

148. Ladenstein $\mathrm{R}$ et al (2011) Dose finding study for the use of subcutaneous recombinant interleukin-2 to augment natural killer cell numbers in an outpatient setting for stage 4 neuroblastoma after megatherapy and autologous stem-cell reinfusion. J Clin Oncol 29:441-448. https://doi.org/10.1200/JCO.2009.23.5465

149. Shimizu K et al (2012) Clinical utilization of postoperative dendritic cell vaccine plus activated T-cell transfer in patients with intrahepatic cholangiocarcinoma. J Hepatobiliary Pancreat Sci 19:171-178. https://doi.org/10.1007/s0053 4-011-0437-y

150. Shimizu K et al (2014) Postoperative dendritic cell vaccine plus activated T-cell transfer improves the survival of patients with invasive hepatocellular carcinoma. Hum Vaccin Immunother 10:970-976

151. Aranda F et al (2014) Trial watch: adoptive cell transfer for anticancer immunotherapy. Oncoimmunology 3:e28344. https ://doi.org/10.4161/onci.28344

152. Cata JP et al (2017) Inflammation and pro-resolution inflammation after hepatobiliary surgery. World J Surg Oncol 15:152. https://doi.org/10.1186/s12957-017-1220-6

153. Martin CR et al (2014) Resolvin D1 and lipoxin A4 improve alveolarization and normalize septal wall thickness in a neonatal murine model of hyperoxia-induced lung injury. PLoS ONE 9:e98773. https://doi.org/10.1371/journal.pone.0098773

154. Ueda $\mathrm{T}$ et al (2014) Combination therapy of 15-epi-lipoxin A4 with antibiotics protects mice from Escherichia coli-induced sepsis. Crit Care Med 42:e288-e295. https://doi.org/10.1097/ CCM.0000000000000162

155. Benish $\mathrm{M}$ et al (2008) Perioperative use of beta-blockers and COX-2 inhibitors may improve immune competence and reduce the risk of tumor metastasis. Ann Surg Oncol 15:20422052. https://doi.org/10.1245/s10434-008-9890-5

156. Qadri SS et al (2005) Surgically induced accelerated local and distant tumor growth is significantly attenuated by selective COX-2 inhibition. Ann Thorac Surg 79:990-995. https://doi. org/10.1016/j.athoracsur.2004.07.042 (discussion 990-995)

157. Shaashua L et al (2017) Perioperative COX-2 and beta-adrenergic blockade improves metastatic biomarkers in breast cancer patients in a phase-II randomized trial. Clin Cancer Res 23:4651-4661. https://doi.org/10.1158/1078-0432. CCR-17-0152

158. Zhou L et al (2016) Propranolol attenuates surgical stressinduced elevation of the regulatory $\mathrm{T}$ cell response in patients undergoing radical mastectomy. J Immunol 196:3460-3469. https://doi.org/10.4049/jimmunol.1501677

159. Melhem-Bertrandt A et al (2011) Beta-blocker use is associated with improved relapse-free survival in patients with triplenegative breast cancer. J Clin Oncol 29:2645-2652. https://doi. org/10.1200/JCO.2010.33.4441

160. Forget $\mathrm{P}$ et al (2010) Do intraoperative analgesics influence breast cancer recurrence after mastectomy? A retrospective analysis. Anesth Analg 110:1630-1635. https://doi. org/10.1213/ANE.0b013e3181d2ad07

161. van der Hage JA et al (2001) Improved survival after one course of perioperative chemotherapy in early breast cancer patients. long-term results from the European Organization for 
Research and Treatment of Cancer (EORTC) Trial 10854. Eur J Cancer 37:2184-2193

162. Sertoli MR et al (1995) Randomized cooperative study of perioperative chemotherapy in breast cancer. J Clin Oncol 13:2712-2721. https://doi.org/10.1200/JCO.1995.13.11.2712

163. Nissen-Meyer R, Kjellgren K, Malmio K, Mansson B, Norin T (1978) Surgical adjuvant chemotherapy: results with one short course with cyclophosphamide after mastectomy for breast cancer. Cancer 41:2088-2098

164. Shantha Kumara HM et al (2009) Perioperative GMCSF limits the proangiogenic plasma protein changes associated with colorectal cancer resection. Eur J Surg Oncol 35:295-301. https://doi.org/10.1016/j.ejso.2008.07.012
165. NSCLC Meta-analysis Collaborative Group (2014) Preoperative chemotherapy for non-small-cell lung cancer: a systematic review and meta-analysis of individual participant data. Lancet 383:1561-1571. https://doi.org/10.1016/S0140-6736(13)62159 $-5$

166. Nordlinger B et al (2013) Perioperative FOLFOX4 chemotherapy and surgery versus surgery alone for resectable liver metastases from colorectal cancer (EORTC 40983): long-term results of a randomised, controlled, phase 3 trial. Lancet Oncol 14:12081215. https://doi.org/10.1016/S1470-2045(13)70447-9

167. Emmenegger U, Kerbel RS (2010) Cancer: chemotherapy counteracted. Nature 468:637-638. https://doi.org/10.1038/468637a 